\title{
ỨNG DỤNG CÔNG NGHẸ VIỄN THÁM TRONG THÀNH LẬP BẢN ĐỒ LỚP PHỦ MẠ́T ĐẤT THEO HƯỚNG DÃ̃N CỦA IPCC PHỤC VỤ CÔNG TÁC GIÁM SÁT TÀI NGUYÊN MÔI TRƯỜNG VÀ BIẾN ĐỔI KHÍ HậU
}

\author{
TS. TRẦ TUÂN NGỌC ${ }^{(1)}, K S$. VŨ TH! TUYÉT ${ }^{(1)}$, \\ ThS. NGUYẼ̃N THANH NGA ${ }^{(1)}$, ThS. NÔNG TH! OANH(2) \\ ${ }^{(1)}$ Cục Viễn thám Quốc gia

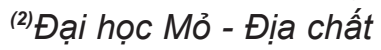

\section{Tóm tắt:}

Lớp phủ mặt đất giữ vai trò quan trọng trong công tác giám sát tài nguyên môi trường và biến đổi khí hậu. Những thay đổi của các đối tượng trên bề mặt đất có mối liên hệ mật thiết đến những biến động về môi trường và khí hậu. Phân tích biến động của lớp phủ mặt đất là một trong những ứng dụng điển hình của công nghệ viễn thám trong giám sát tài nguyên, thiên nhiên và biến đổi khí hậu. Việc phân tích chính xác và kịp thời những biến động trên bề mặt Trái đất đóng vai trò quan trọng trong việc tìm hiểu mối quan hệ và tác động qua lại giữa con người và tự nhiên, nhằm phục vụ công tác quản lý của các cấp, các ngành. Với ưu thế vượt trội, công nghệ viễn thám cho phép giám sát, đánh giá nhanh sự thay đổi lớp phủ trên diện rộng mà những phương pháp truyền thống khó đạt được. Bài báo này chúng tôi muốn đặt vấn đề cho việc nghiên cứu phương pháp thành lập bản đồ lớp phủ mặt đất bằng công nghệ viễn thám, mục đích để tạo ra bộ dữ liệu cơ sở phục vụ công tác giám sát tài nguyên thiên nhiên và biến đổi khí hậu.

\section{1. Đặt vấn đề}

Hiện nay chúng ta thường xuyên đọc và nghe thấy khái niệm sử dụng đất (landuse) và khái niệm lớp phủ mặt đất (landcover). Tuy nhiên trong các chú giải và phân loại đất hiện nay, hai khái niệm này thường bị lẫn lộn, chưa có định nghĩa rõ ràng. Theo định nghĩa của tổ chức nông lương thế giới (FAO) khái niệm phủ mặt đất được hiểu là sự tồn tại của các thực thể hữu hình trên bề mặt đất, các thực thể này có thể được tạo ra bởi con người hoặc tự nhiên. Nói cách khác phủ mặt đất là trạng thái vật lý của bề mặt đất có thể quan sát được, tạo thành bởi các đối tượng tự nhiên và nhân tạo bao quanh Trái đất [1]. Trường Đại học Michigan, Mỹ, định nghĩa phủ mặt đất là lớp phủ vật chất quan sát được khi nhìn từ mặt đất hoặc thông qua vệ tinh viễn thám, bao

Ngày nhận bài: 07/3/2016 gồm thực vật (mọc tự nhiên hoặc được trồng cấy) và các cơ sở xây dựng của con người (nhà, đường giao thông...) bao phủ bề mặt mặt đất. Nước, băng, đá, các khu vực đất hoang hóa, sa mạc, đất trống hay các dải cát cũng được coi là lớp phủ mặt đất [2]. Như vậy chúng ta có thể hiểu lớp phủ mặt đất có quan hệ mật thiết với các hoạt động kinh tế - xã hội, tài nguyên thiên nhiên và môi trường sống trên Trái đất.

Trong khi đó, sử dụng đất đề cập đến cách thức mà đất được sử dụng bởi con người và môi trường sống, khái niệm này đề cập nhiều tới vai trò chức năng của đất phục vụ các hoạt động kinh tế - xã hội. Sử dụng đất thường được định nghĩa là một loạt các hoạt động về đất đai thực hiện bởi con người, với kế hoạch để có được sản phẩm hoặc lợi ích thông qua việc sử dụng

Ngày chấp nhận đăng: 15/3/2016 
tài nguyên đất. Sử dụng đất đề cập đến mục đích phục vụ của đối tượng đất đai, ví dụ: giải trí, môi trường sống, động vật hoang dã hoặc nông nghiệp, nó không mô tả các đối tượng phủ trên bề mặt Trái đất [2]. Dữ liệu sử dụng đất là thành phần cơ bản của quá trình lập kế hoạch và ra quyết định cho các nhà quản lý nó giúp họ lên kế hoạch cho các hoạt động sử dụng đất phục vụ sự phát triển kinh tế xã hội.

Từ hai định nghĩa trên chúng ta có thể kết luận khái niệm phủ mặt đất khác với khái niệm sử dụng đất, tuy nhiên các đối tượng của chúng lại có sự tương quan mật thiết. Sử dụng đất mô tả cách thức và các hoạt động kinh tế-xã hội của con người xảy ra trên mặt đất, những hoạt động này lại có sự tác động trực tiếp lên bề mặt đất, chính vì vậy mà một số loại hình sử dụng đất cũng là đối tượng của phủ mặt đất. Tuy nhiên, sự khác biệt lớn ở đây là dữ liệu phủ mặt đất có thể được xác định độc lập bằng cách phân tích ảnh viễn thám [2]. Dữ liệu sử dụng đất không thể xác định độc lập từ hình ảnh viễn thám, chúng cần thiết phải kết hợp với các thông tin từ nhà quản lý và các cấp chính quyền.

Mỗi một khu vực khác nhau trên Trái đất đều có loại hình lớp phủ đặc trưng, dưới sự tác động của tự nhiên và con người ở mức độ mạnh, yếu khác nhau dẫn tới việc lớp phủ luôn biến đổi theo thời gian. Sự biến đổi này đang ảnh hưởng trực tiếp đến cuộc sống con người, liên quan tới các chu trình thay đổi khí hậu ở các cấp độ khác nhau, từ cục bộ từng nước, từng khu vực cho đến toàn cầu. Trong bối cảnh các hiện tượng thời tiết cực đoan diễn ra phổ biến, những trận bão, lũ, hạn hán ngày càng gia tăng về cường độ, tần suất, gây ra nhiều tổn thất về người và thiệt hại kinh tế trên toàn cầu. Bên cạnh đó, hiện tượng nắng nóng gia tăng rõ rệt dẫn tới hạn hán, kèm theo là sa mạc hóa xảy ra ở nhiều vùng trên thế giới. Hiện tượng biến đổi khí hậu cũng đang tác động trực tiếp đến sự thay đổi lượng mưa cũng như việc phân bố mưa ở các vùng khác nhau, điều này dẫn đến những thay đổi về dòng chảy của các con sông lớn dẫn tới tần suất và cường độ các trận lũ ngày càng tăng. Với vai trò điều hòa khí hậu toàn cầu, sự thay đổi của lớp phủ mặt đất, bằng cách này hay cách khác, đang có tác động tiêu cực đến sự biến đổi khí.

\section{Tổng quan nghiên cứu lớp phủ mặt đất bằng công nghệ viễn thám}

\subsection{Vai trò của viễn thám trong nghiên cứu lớp phủ mặt đất}

Một trong những công cụ hữu hiệu để phân loại và đánh giá sự biến động lớp phủ mặt đất được áp dụng rộng rãi trên thế giới là công nghệ viễn thám, công nghệ này đặc biệt có ý nghĩa cả về mặt thời gian, không gian, hiệu quả kinh tế và có tính minh bạch dữ liệu rất cao thông qua việc phân loại các quang phổ thu được từ ảnh. Hiện nay, viễn thám đã và đang trở thành phương pháp nghiên cứu lớp phủ phổ biến nhất bởi tính ưu việt những: khả năng cung cấp thông tin trên diện rộng một vùng, toàn lãnh thổ hay cả khu vực; khả năng cung cấp thông tin theo chuỗi thời gian. Bên cạnh đó, tư liệu viễn thám còn có khả năng thu nhận thông ở những khu vực xa xôi hẻo lánh nơi những công nghệ truyền thống gần như khó có khả năng tiếp cận. Với khả năng chụp lặp ở nhiều thời điểm khác nhau công nghệ viễn thám cho phép theo dõi và giám sát biến động của lớp phủ mặt đất phục vụ việc đánh giá thiệt hại do các hiện tượng thiên nhiên cực đoan gây ra như: bão, lũ, hạn hán, ngập lụt..... Ngoài ra, Viễn thám cũng cho phép chúng ta giám sát những biến động lớp phủ do yếu tố nhân sinh gây lên như: mức độ đô thị hóa; cháy rừng; thay đổi cơ cấu cây trồng; mức độ sa mạc hóa; các vùng ngập mặn...

\subsection{Hệ thống phân loại trong nghiên cứu lớp phủ mặt đất}


Công việc quan trọng hàng đầu trong việc xây dựng bản đồ lớp phủ mặt đất là việc xây dựng hệ thống phân loại các kiểu hiện trạng phủ mặt đất. Phân loại thực chất là việc xác định rõ tiêu chuẩn để chuẩn đoán và sắp xếp các đối tượng thành các nhóm trên cơ sở mối quan hệ của các đối tượng [3]. Để tạo điều kiện thuận lợi cho việc khai thác và sử dụng các lớp thông tin cũng như việc đảm bảo tính thống nhất về nội dung thông tin, cần thiết phải có hệ thống phân loại và mã hóa các đối tượng theo ký hiệu màu sắc. Bên cạnh đó, một hệ thống phân loại khung phải được định nghĩa tên của các nhóm lớp và các tiêu chuẩn dùng để phân biệt chúng cũng như mối quan hệ giữa các nhóm lớp. Phân loại như vậy đòi hỏi phải định nghĩa ranh giới các lớp một cách rõ ràng, chính xác, có thể định lượng và dựa trên các tiêu chí khách quan. Khung phân loại này phải làm cơ sở để các xây dựng nên các hệ thống tiểu phân loại lớp phủ mặt đất cho cả nước, từng vùng hay từng địa phương.

Ở nước ta trong những năm gần đây đã quan tâm nhiều đến việc thành lập bản đồ lớp phủ mặt đất, tuy nhiên chúng ta vẫn chưa có quy định thống nhất hệ phân loại của bản đồ lớp phủ mặt đất. Chính vì vậy, hướng dẫn của 2006 IPCC (Intergovernmental Panel on Climate Change) cho phần Nông nghiệp, Rừng và các loại đất khác (AFOLU) được dùng làm tài liệu chính để xây dựng hệ thống phân loại lớp phủ mặt đất cho nghiên cứu này.

\section{Dữ liệu và phương pháp xử lý dữ liệu \\ 3.1. Tổng quan chung khu vực nghiên cứu}

Khu vực nghiên cứu được lựa chọn thuộc miền bắc Lào bao gồm một phần diện tích các tỉnh Xayabouri, Luangprabang, Vientiane và Thủ đô Vientiane: Tỉnh
Luangprabang có diện tích 16.875 km², thành phố nằm trên bán đảo hẹp là giao của sông Mekong chảy từ phía Nam xuống phía Tây thànhh phố và sông Mae Kok, cùng một nhánh của sông Mekong chảy từ phía Đông; Tỉnhh Xayabouri với diện tích 16.389 km², tỉnh này nằm ở phía Tây Bắc gồm toàn bộ diện tích lưu vực phía Tây của sông Mekong, địa hình khu vực này tương đối hiểm trở với dãy Luangprabang chạy dọc theo hướng Bắc Nam và tạo thànhh biên giới tự nhiên ngăn cách với cao nguyên của Thái Lan; Tỉnh Vientiane có diện tích 15.927 $\mathrm{km}^{2}$, nằm ở phía Tây Bắc Lào, phần lớn diện tích phía Nam của tỉnh này nằm trong khu bảo tồn đa dạng sinh học Phou Khao Khouay, phía Đông là đỉnh núi Phou Bia cao nhất của Lào, các sông chính chảy qua tỉnh gồm có Nam Song, Nam Ngum và Nam Lik; Thủ đô Vientiane là thủ phủ và thành phố rộng nhất của Lào. Thành phố này có diện tích $3.920 \mathrm{~km}^{2}$, nằm ở tả ngạn sông Mekong bên kia là Thái Lan. (xem hình 1)

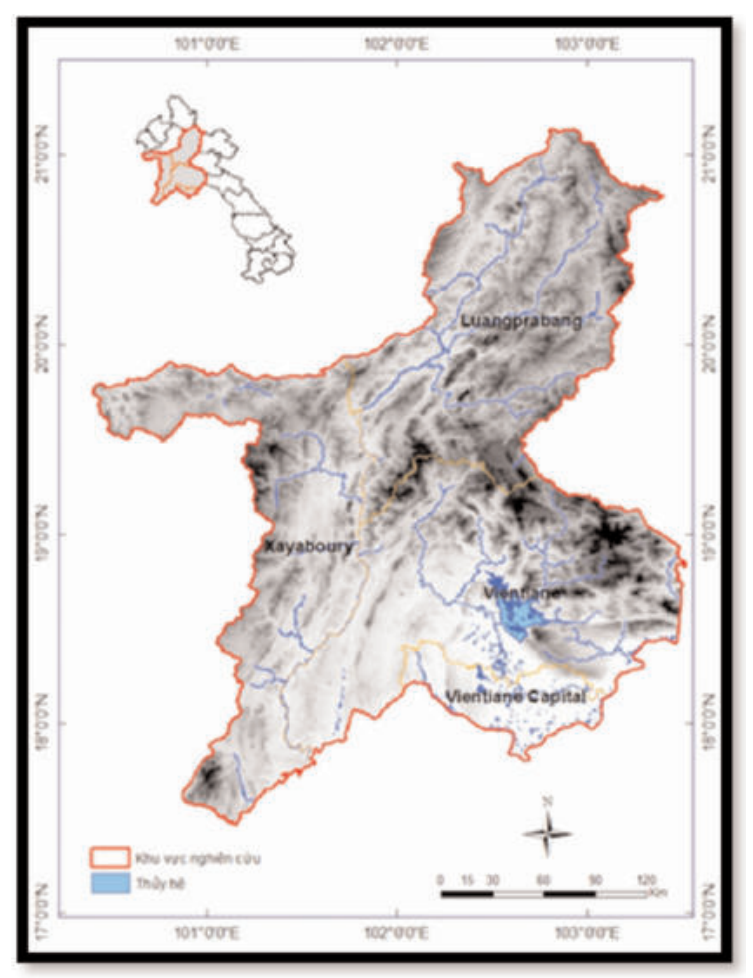

Hình 1: Sơ đồ khu vực nghiên cứu 
Đây là khu vực nhiệt đới gió mùa trong năm khí hậu chia thành hai mùa rõ rệt, mùa mưa từ tháng 5 đến tháng 10 , mùa khô từ tháng 11 đến cuối tháng 4 năm sau. Nhiệt độ trung bình cả năm khoảng $27^{\circ} \mathrm{C}$, đầu mùa khô là thời điểm khí hậu nóng nhất trong năm khi đó nhiệt độ dao động từ $29^{\circ} \mathrm{C}$ đến $38^{\circ} \mathrm{C}$, tháng 11 đến tháng 2 là thời gian có nhiệt độ thấp hơn, các khu vực núi cao có thể xuống thấp tới $10^{\circ} \mathrm{C}$. Lượng mưa trung bình hàng năm trong khu vực giao động trong khoảng $3.000 \mathrm{~mm}$.

Do đặc điểm địa hình nên phần lớn lớp phủ mặt đất của khu vực này là rừng, đặc biệt là tỉnh Luangprabang. Đây là nguồn tài nguyên lớn có ý nghĩa cực kỳ quan trọng đối với sự phát triển bền vững và cân bằng sinh thái của khu vực. Tuy nhiên, để phát triển kinh tế như làm thủy điện, khai thác gỗ, trồng cây công nghiệp dẫn tới một phần diện tích rừng đã bị tàn phá, đây là nguyên nhân chính làm thay đổi lớp phủ trong khu vực nghiên cứu.

\subsection{Dữ liệu sử dụng}

Nguồn dữ liệu ảnh sử dụng cho nghiên cứu này là 12 cảnh ảnh Landsat $7+\mathrm{ETM}$ (chụp năm 20000) phục vụ cho xây dựng bản đồ lớp phủ năm 2000, 12 cảnh ảnh 7+ETM (chụp năm 2010) phục vụ cho xây dựng bản đồ lớp phủ năm 2010. Dữ liệu ảnh LANDSAT được cung cấp miễn phí trên trang http://earthexplorer.usgs.gov, Cục khảo sát địa chất Hoa Kỳ (USGS). Các cảnh ảnh này đã được định vị trong hệ tọa độ WGS84.

Bản đồ địa hình tỷ lệ 1/100.000 của Lào do Nhật Bản giúp đỡ trong dự án thành lập cơ sở dữ liệu bản đồ cơ bản lưu vực sông Mekong giai đoạn từ năm 1998 - 2003 và hệ thống bản đồ địa hình tỷ lệ $1 / 100.000$ do Liên Xô cũ thành lập có hiện chỉnh địa vật bằng ảnh hàng không chụp năm 1999 và ảnh vũ trụ độ phân giải $20 \mathrm{~m}$ chụp năm 1999-2000. Đây là nguồn tài liệu dùng để tham khảo và hỗ trợ công tác nắn chỉnh ảnh về hệ tọa độ quốc gia Lào và dùng trong công tác kiểm định chất lượng phân loại.

\subsection{Phương pháp xử lý dữ liệu}

Toàn bộ quá trình xử lý các số liệu và phân tích, lưu trữ kết quả nghiên cứu thực hiện trên phần mềm xử lý ảnh ERDAS Imagine. Phương pháp phân loại có kiểm định với thuật toán phân loại xác suất tối ưu Maximum Likelihood được sử dụng trong nghiên cứu này. Đây là một trong những phương pháp phân loại có giám sát phổ biến nhất thường dùng với dữ liệu viễn thám. Phân loại có kiểm định là phương pháp xác suất có khả năng sắp xếp những pixel do người sử dụng định nghĩa thành những lớp khác nhau, trong đó tất cả các pixel trên ảnh được nhận dạng thông qua ký hiệu phổ tương ứng với mục đích nhận ra là sự đồng nhất, những mẫu đại diện mang nét đặc trưng của từng đối tượng chúng ta muốn phân loại. Việc chỉnh sửa bổ sung thực hiện trên từng vùng đã phân loại dựa trên phân tích hình ảnh bằng và kinh nghiệm của các chuyên gia và đặc trưng riêng của từng khu vực.

Đánh giá độ chính xác phân loại các đối tượng trong nghiên cứu sử dụng phương pháp ma trận sai số Kappa Khat. Bước đầu tiên trong quá trình kiểm định là xác định các khu vực có ảnh độ phân giải cao trên Google Earth năm 2000 và 2010. Điểm kiểm tra được tạo ngẫu nhiên trong ArcGIS, sau đó được tạo thành các vùng đệm (Buffered) kích thước 2ha. Các vùng đệm này được chuyển đến một tệp tin $\mathrm{KML}$ và nạp vào Google Earth. Qua các phân tích trực quan trên ảnh độ phân giải cao, tính chất của lớp phủ được gán vào các điểm kiểm tra ngẫu nhiên. Số lượng điểm kiểm tra này sau đó được kiểm định thuộc tính một lần nữa với dữ liệu bản đồ địa hình 1:100.000 và một số dữ liệu cùng chu kỳ được thu thập từ Cục Đo đạc và Bản đồ Lào. Quá trình kiểm định được thực hiện 
cho toàn khu vực trên tổng số 284 điểm lấy mẫu cho năm 2000 và 246 điểm cho năm 2010.

\section{Kết quả và thảo luận}

\subsection{Hệ thống phân loại lớp phủ mặt đất}

Theo hướng dẫn của 2006 IPCC, lớp phủ đặc trưng của Trái đất được chia làm 6 nhóm lớp đối tượng, nội dung của 6 nhóm lớp đối tượng được tóm tắt trong bảng 1 (xem bảng 1), riêng phần tiểu phân loại sẽ tùy thuộc vào quyết định của mỗi quốc gia [4]. Do đó, trong nghiên cứu này chưa đề cập đến phần tiểu phân loại lớp phủ.

Kết quả trong bảng 1 cho thấy hệ thống phân loại trên đã thể hiện đầy đủ các nhóm đối tượng phủ mặt đất, các nhóm đối tượng này đều dễ dàng thu nhận được từ ảnh viễn thám. Sự mã hóa và số hóa các kiểu lớp phủ là cần thiết nhằm mục đích làm dễ dàng hơn việc ứng dụng vào việc phân loại và đánh giá các đối tượng sau này. Bảng 2 quy định mã hóa và số hóa các đối tượng lớp phủ trong bảng 1. (xem bảng 2)

\subsection{Bản đồ lớp phủ mặt đất}

Hình $2 a$ và hình $2 b$ là kết quả thu được thông qua việc phân loại thực phủ từ ảnh Landsat theo bảng phân loại (xem bảng 1), biên tập và thể hiện các yếu tố trên bản đồ theo thông số màu (xem bảng 2).

Bảng 3, ma trận đánh giá độ chính xác năm 2000 chỉ ra phần trăm sai số lớn rợ vào 3 nhóm đối tượng: Rừng; Cây trồng; Cỏ. Ba nhóm đối tượng này chiếm $18.3 \%$ trên tổng số $22.2 \%$ tổng phần trăm sai số của toàn khối. Riêng đối tượng rừng chiếm sai số lớn nhất, 19 điểm sai trên tổng số 84 điểm lấy mẫu. Nguyên nhân của sự nhầm lẫn này đến từ việc ba đối tượng có sự tương đồng rất lớn về phổ. (xem bảng 3)

\section{Bảng 1: Bảng phân loại các đối tượng phủ mặt đất}

\begin{tabular}{|c|l|l|}
\hline STT & Tên nhóm lớp & \multicolumn{1}{c|}{ Đối tượng } \\
\hline 1 & Lớp rừng & Bao gồm thảm thực vật đạt các tiêu chí xác định rừng của FAO. \\
\hline 2 & Lớp cây trồng & $\begin{array}{l}\text { Bao gồm tất cả các thảm thực vật là cây trồng nông nghiệp và các hệ thống nông } \\
\text { nghiệp, nơi các cấu trúc thảm thực vật giảm xuống dưới ngưỡng được sử dụng } \\
\text { cho nhóm lớp rừng. }\end{array}$ \\
\hline 3 & Lớp cỏ & $\begin{array}{l}\text { Bao gồm đồng cỏ tự nhiên, các loại thảo mộc rơi xuống dưới ngưỡng giá trị phân } \\
\text { loại rừng. }\end{array}$ \\
\hline 4 & $\begin{array}{l}\text { Lớp dân cư và } \\
\text { cơ sở hạ tầng }\end{array}$ & $\begin{array}{l}\text { Bao gồm tât cả các đối tượng đất đai liên quan tới dân cư và cơ sở hạ tầng nhu: } \\
\text { các khu dân cư cư trú; hệ thống đường giao thông; các công trình công cộng; các } \\
\text { khu công nghiệp tập trung... }\end{array}$ \\
\hline 5 & Lớp ngập nướcc & $\begin{array}{l}\text { Bao gồm các khu vực được bao phủ hoặc có hàm lượng nước bão hòa trong đất } \\
\text { suốt cả năm. }\end{array}$ \\
\hline 6 & Lớp đất trống & Bao gồm các khu vực đất trống, đồi trọc, đá sỏi, cát.... \\
\hline
\end{tabular}

Bảng 2: Bảng mã hóa và số hóa các đối tượng lớp phủ mặt đất

\begin{tabular}{|l|c|c|c|c|}
\hline & \multirow{2}{*}{ Mã ký hiệu } & \multicolumn{3}{|c|}{ Thông số màu } \\
\cline { 3 - 5 } & & Red & Green & Blue \\
\hline Lớp rừng & $\mathrm{F}$ & 56 & 168 & 0 \\
\hline Lớp cây trồng & $\mathrm{C}$ & 211 & 255 & 190 \\
\hline Lớp cỏ & $\mathrm{G}$ & 230 & 230 & 130 \\
\hline Lớp dân cư và cơ sở hạ tầng & $\mathrm{S}$ & 255 & 0 & 0 \\
\hline Lớp ngập nước & $\mathrm{W}$ & 151 & 219 & 242 \\
\hline Lớp đất trống & $\mathrm{O}$ & 255 & 255 & 254 \\
\hline
\end{tabular}




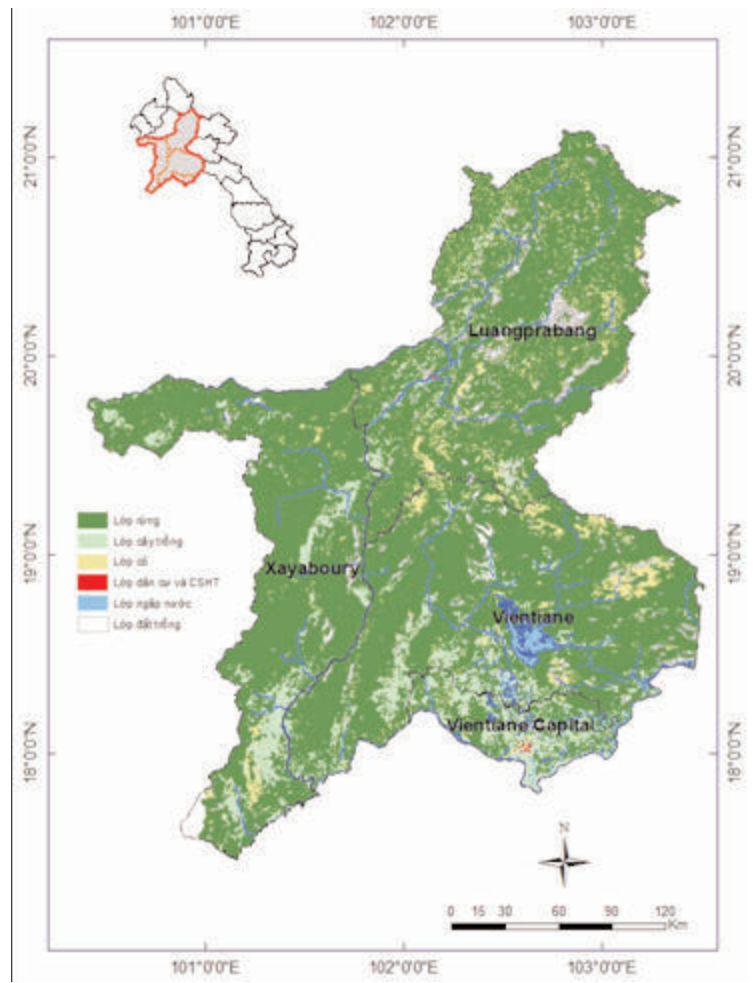

Hình 2a: Bản đồ lớp phủ mặt đất năm 2000

Kết quả ma trận đánh giá độ chính xác năm 2010 (xem bảng 4) cho thấy việc phân loại đạt độ chính xác cao hơn so với năm 2000. Tuy nhiên, 3 nhóm đối tượng: Rừng; Cây trồng; Cỏ vẫn chiến phần lớp sai số, nguyên nhân vẫn đến từ sự tương đồng về phổ của các nhóm đối tượng này. Tổng phần trăm sai số của 3 đối tượng này chiếm $16.3 \%$ trên tổng số $20.7 \%$ sai số của toàn khối.

Ma trận đánh giá độ chính xác đã chứng minh bản đồ lớp phủ mặt đất xây dựng từ tư liệu ảnh viễn thám đạt độ chính xác cao. Cụ thể, độ chính xác tổng đạt trên $75 \%$ kết quả kiểm tra ngẫu nhiên cho cả 2 chu ký cho thấy phương pháp này đạt giới hạn độ chính xác khá cao. Với hệ số $\mathrm{K}=0.79$ cho thấy kết quả phân loại năm 2010 rất đạt độ chính xác rất cao trong thang đánh giá sai số của phương pháp Kappa Khat [6]. Kết quả đánh giá độ chính xác cũng chỉ ra nhóm đối tượng cỏ, cây trồng, rừng và dân

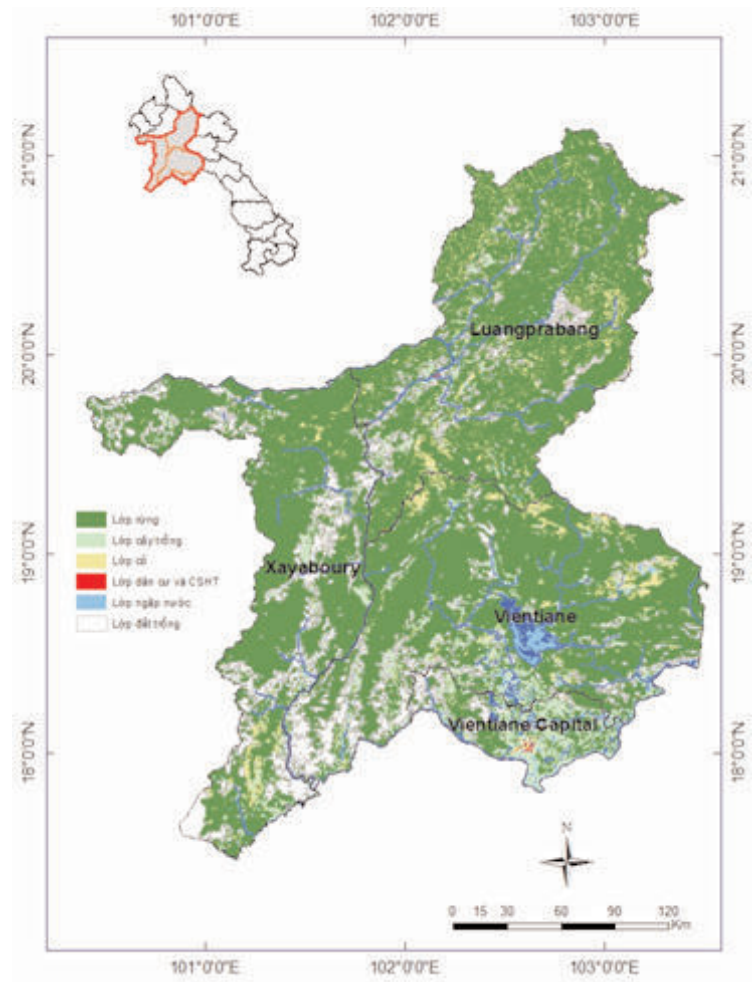

Hình 2b: Bản đồ lớp phủ mặt đất năm 2010

cư rất dễ nhầm lẫn, nguyên nhân nhầm lẫn là do đặc thu sự xen kẽ giữa các đối tượng này trên thực tế cộng với sự tương đồng về phổ là rất cao giữa các nhóm đối tượng, nguyên nhân này rất khó tránh khỏi thậm chí cả với các phương pháp truyền thống.

\section{Kết luận}

Nghiên cứu này bước đầu đưa ra các định nghĩa và xây dựng hệ thống phân loại các nhóm lớp phủ mặt đất theo chuẩn quốc tế, cụ thể là các định nghĩa của $F A O$ và những hướng dẫn phân loại của IPCC, về cơ bản hệ thống này phù hợp với các đối tượng lớp phủ mặt đất nói chung và của Lào nói riêng. Để kết quả của nghiên cứu có thể ứng dụng rộng rãi, cần thiết phải có những nghiên cứu để hoàn thiện hệ thống phân loại hoàn chỉnh trong đó bao gồm phần tiểu phân loại. Trong bối cảnh sự biến đổi khí hậu đang diễn ra trầm trọng việc giám sát sự biến động của lớp phủ mặt đất là vô cùng cấp thiết. Việc đưa ra những phân tích 
Bảng 3: Ma trận đánh giá độ chính xác phân loại lớp phủ năm 2000

\begin{tabular}{|c|c|c|c|c|c|c|c|}
\hline & F & C & G & W & S & O & \\
\hline F & 65 & 5 & 11 & & & & 81 \\
\hline $\mathbf{C}$ & 6 & 68 & 3 & 2 & 4 & & 83 \\
\hline $\mathbf{G}$ & 11 & 5 & 22 & 1 & 2 & & 41 \\
\hline $\mathbf{W}$ & 2 & 1 & 2 & 27 & & 1 & 33 \\
\hline $\mathbf{S}$ & & 6 & & 2 & 30 & & 38 \\
\hline $\mathbf{O}$ & & & & & & 8 & 8 \\
\hline & 84 & 85 & 38 & 32 & 36 & 9 & 284 \\
\hline
\end{tabular}

chính xác và kịp thời biến động trên bề mặt Trái đất đóng vai trò quan trọng giúp nhà hoạch định chính sách có những quyết định kịp thời nhằm giảm thiểu những tác động tiêu cực từ hiện tượng thời tiết cực đoan như bão lũ, hạn hán cũng như các tác động khác từ hiện tượng biến đổi khí hậu. Do đó, việc xây dựng một hệ thống theo dõi biến động lớp phủ mặt đất bằng công nghệ viễn thám là yêu cầu cần thiết của mỗi Quốc gia. $\bigcirc$

\section{Tài liệu tham khảo}

[1]. Antonio Di Gregorio and Louisa J.M. Jansen, Land Cover Classification System (LCCS), FAO Land and Water Development Division.

[2]. Ryan Coffey, January 18, 2013, The difference between "land use" and "land cover", Michigan State University Extension.

[3]. Antonio Di Gregorio and Louisa J.M. Jansen, Land Cover Classification System Classification concepts and user manual Software version (2), Food and Agriculture Organization of the United Nations.

[4]. Edited by Simon Eggleston, Leondro Buendia, Kyoko Miwa, Todd Ngara and Kiyoto Tanabe. Volume 4 Agriculture, Forestry and Other Land Use, 2006 IPCC
Bảng 4: Ma trận đánh giá độ chính xác phân loại lớp phủ năm 2010

\begin{tabular}{c|c|c|c|c|c|c|c} 
& $\mathbf{F}$ & $\mathbf{C}$ & $\mathbf{G}$ & $\mathbf{W}$ & $\mathbf{S}$ & $\mathbf{O}$ & \\
\hline $\mathbf{F}$ & $\mathbf{6 2}$ & 2 & 6 & 1 & 1 & & 72 \\
\hline $\mathbf{C}$ & 5 & $\mathbf{6 5}$ & 7 & 2 & 2 & 1 & 82 \\
\hline $\mathbf{G}$ & 8 & 6 & $\mathbf{3 4}$ & 1 & & 2 & 51 \\
\hline $\mathbf{W}$ & 1 & 2 & & $\mathbf{1 4}$ & & & 17 \\
\hline $\mathbf{S}$ & & 3 & & & $\mathbf{1 5}$ & & 18 \\
\hline $\mathbf{O}$ & & & & & & $\mathbf{6}$ & 6 \\
\hline & 76 & 78 & 47 & 18 & 18 & 9 & 246 \\
\hline
\end{tabular}

Guidelines for National Greenhouse Gas Inventories.

[5]. James R. Anderson, Ernest E. Hardy, John T. Roach, and Richard E. Withmer, A Land Use And Land Cover Classification System For Use With Remote Sensor Data, Geological Survey Professional Paper 964.

[6]. Hoàng Xuân Thành, Thành lập bản đồ thảm thực vật trên cơ sở phân tích, xử lý ảnh viễn thám, Tạp chí Khoa học kỹ thuật Thủy lợi và Môi trường, S. 29 (2010).

[7]. Dương Tiến Đức, Joosang Chung, Bước đầu xây dựng hệ thống phân loại hiện trạng sử dụng với các số liệu thu thập được từ ảnh vệ tinh tại lưu vực phòng hộ đầu nguồn sông Đà, Việt Nam, Tạp chí khoa học Lâm nghiệp.

[8]. Thông tư 34/2009/TT-BNNPTNT, Thông tư Quy định tiêu chí xác định và phân loại rừng, Bộ Nông nghiệp và Phát triển nông thôn.

[9]. Quyết định 23/2007/QĐ-BTNMT, Ban hành ký hiệu bản đồ hiện trạng sử dụng đất và bản đồ quy hoạch sử dụng đất. Bộ Tài nguyên và Môi trường.

[10] https://climatedataguide.ucar.edu/climate-data/ceres-igbp-land-classification. $\bigcirc$

(Xem tiếp trang 49) 